\title{
Effect of gross morphology on modern planktonic foraminiferal test strength under compression
}

\author{
Janet E. Burke* \& Pincelli M. Hull \\ Department of Geology and Geophysics, Yale University, 210 Whitney Avenue, New Haven, CT 06511, USA \\ * Correspondence: janet.burke@yale.edu
}

\begin{abstract}
Planktonic foraminifera are a source of important geochemical, palaeoceanographic, and palaeontological data. However, many aspects of their ecology remain poorly understood, including whether or not gross morphology has an ecological function. Here, we measure the force needed to crush multiple planktonic foraminiferal morphotypes from modern core top and tow samples. We find significant differences in the resistance of different morphotypes to compressional force. Three species, Globorotalia tumida (biconvex, keeled), Menardella menardii (discoidal, keeled), Truncorotalia truncatulinoides (conical, keeled), require on average $59 \%$ more force $(1.07 \mathrm{v} .0 .47 \mathrm{~N})$ to crush than the least resistant species (Orbulina universa and Trilobatus sacculifer) in core-top samples. Towed samples of pre-gametogenic individuals also show significant differences of the same magnitude $(0.693 \mathrm{v} .0 .53 \mathrm{~N})$ between the conical (T. truncatulinoides) and globular/ spherical morphologies (Globoconella inflata and O. universa). We hypothesize that the greater compressional strength of certain shapes confers a fitness advantage against predators and could contribute to the repeated, convergent evolution of keeled, conical and bi-convex forms in planktonic foraminifer lineages.
\end{abstract}

Keywords: planktonic foraminifera, morphology, predation, pelagic ecology, iterative evolution

Supplementary material: Raw data for all crushing experiments, wall thickness measurements, and results for all pair-wise Kolmogorov-Smirnov Tests are available at https://doi.org/10.6084/m9.figshare.c.3725236.v1

Received 10 February 2016; accepted 19 June 2016

Throughout their fossil record, planktonic foraminifera have repeatedly converged on a limited number of gross morphologies (i.e. morphotypes). Characteristic morphological features, such as reinforced 'keeled' margins and elongated 'digitate' chambers, have evolved, gone extinct and re-evolved in different lineages in a process known as iterative evolution (Cifelli 1969; Norris 1991; Coxall et al. 2007). The characteristic evolutionary sequence leads from a relatively simple, globular (globigerine) form to a more derived morphotype like those including keeled margins and biconvex or conical forms (Cifelli 1969; Norris 1991).

This pattern of iterative evolution suggests that there may be adaptive advantages to different morphologies, but what these advantages might be is still unclear. In a 1979 review, Lipps presents five hypotheses to account for the ubiquity of convergent evolution in planktonic foraminifera: (1) there is a limited number of possible forms (i.e. convergence is inevitable); (2) physical forces particularly surface tension - shape foraminiferal tests; (3) test shape relates to buoyancy control; (4) test shape regulates orientation in the water to reduce settling speed; and (5) some morphologies provide greater defence against predation (Lipps 1979). The first two hypotheses were immediately rejected by Lipps as having already been disproven. In the first case, Lipps referenced Loeblich \& Tappan's (1964) illustration of the morphological diversity of planktonic foraminifera to argue against limits on the number of possible foraminiferal forms. More recent modelling studies suggest this argument may be premature, as they show that much of the theoretical foraminiferal morphospace has been exploited repeatedly (Tyszka \& Topa 2005; Tyszka 2006). In short, morphological constraint can no longer be so completely discounted. For the second case, put forth by Thompson (1961), Lipps argues that surface tension alone is an oversimplification of the factors that affect cell dimensions and is insufficient to explain the range of morphologies. Foraminiferal gross morphology is often attributed to hydrodynamic controls, including buoyancy, settling and preferred orientation (Marsalek et al. 1969; Lipps 1979; Caromel et al. 2014), the third and fourth hypotheses in Lipps (1979). Multiple factors affect buoyancy, including the composition of cytoplasm, the volume of the test occupied by the living cytoplasm, and the test density and weight (Marsalek et al. 1969; Lipps 1979). Together these factors can determine whether an individual sinks, floats or maintains its depth habitat. Likewise, individuals can also reduce their sinking speed by adopting and maintaining specific body orientations (Lipps 1979). This was extensively explored in a 2014 study by Caromel and colleagues, where they used hydrodynamic models to conclude that buoyancy control and orientation can require very minor morphological changes in test dimensions and density relative to those observed (Caromel et al. 2014). In other words, neither explanation can account for the range of morphologies observed in fossil and living taxa.

The third viable hypothesis of Lipps - that different morphologies serve to prevent or limit selective predation - has remained largely unexplored, even though zooplankton predators exert heavy selective pressure in the pelagic realm in general (Lipps 1979; Smetacek 2001). Diatoms - planktonic photoautotrophs with siliceous tests called 'frustules' - also have a wide array of frustule shapes and structures. It has been hypothesized that these shapes deter mesoplankton grazers, such as pelagic copepods and euphausids (Smetacek 2001; Hamm et al. 2003). The resistance of diatoms to crushing has been tested experimentally and it has been shown that the frustules can resist surprisingly high crushing forces of up to $7 \mathrm{~N} \mathrm{~mm}^{-2}$ (Hamm et al. 2003). Moreover, the force needed to crush diatom frustules varies among species of different shapes, potentially 
offering different levels of defence (Hamm et al. 2003). The same defensive benefits and variation among morphologies may apply to planktonic foraminifera (Lipps 1979; Hemleben et al. 1989) but have yet to be tested.

There are reasons to suspect that selective predation may play a role in shaping foraminiferal morphology. Some features of planktonic foraminifera, such as the pyramidal shape of Truncorotalia truncatulinoides or the long, bulky spikes of the extinct Hantkenina mexicana, may be unwieldy or hard to bite and crush for a zooplankton predator, causing the predator to preferentially feed on unarmoured individuals. Even small differences in the amount of time a predator spends trying to capture and ingest its prey (i.e. handling time) can affect optimal foraging behaviour of selective zooplankton predators and the rate at which they can cull populations of their prey species (Holling 1959; Chang \& Hanazato 2005). Arthropod predators, such as copepods and crabs, have been observed to feed preferentially on easier to crush or open-shelled prey when the option is available (Boulding 1984; Katz 1985; Chang \& Hanazato 2005). Handling time can shape population size over extended time-scales through differential mortality rates by morphotype (Holling 1959; Werner \& Hall 1979; Jeschke et al. 2002; Chang \& Hanazato 2005). Even if the bulk of predation pressure on planktonic foraminifera were by indiscriminant feeders (like filter-feeding fish), a small proportion of selective feeding is enough to cause differential survivorship due to morphology. Along these lines, there have been anecdotal accounts of crushed planktonic foraminifera in the guts of arthropods (Bé \& Hutson 1977; Lipps 1979; Hemleben et al. 1989).

A few published studies have explored the resistance of foraminifera to compressional forces and found differences among morphotypes (Whetmore 1987; Whetmore \& Plotnick 1992; Pearson et al. 2015). In an experiment on benthic foraminifera, crushing resistance was positively correlated with test diameter and wall thickness in several of the species tested, and species with biconvex morphologies (Elphidiella hannai, Islandiella limabata and Oolina borealis) were generally the most resistant to crushing (Whetmore 1987). Another study related crushing resistance to wave-stress in the benthic Archaias angulatus, Amphistgina gibbosa and Laevipeneroplis proteus (Whetmore \& Plotnick 1992) and found that the strongest species occurred in the most dynamic benthic environments. This relationship also held true within populations of the same species, Archaias angulatus. More recently, in the only crushing study to date on planktonic foraminifera, Pearson et al. (2015) explored the compressional forces needed to crack planktonic foraminiferal tests. The aim was to determine whether diagenetically recrystallized fossil tests of two different species, Cribrohantkenina inflata and Turborotalia cerroazulensis, were less resistant to compression than unaltered fossil tests. They found that unaltered tests were stronger than altered tests and that the more conical species, T. cerroazulensis, was stronger than the more globular species.

Inspired by the report by Pearson et al. (2015), we herein test whether morphologically distinct, well-preserved modern planktonic foraminiferal tests vary in their resistance to compressional forces (i.e. 'crushing resistance'). The eight species used in this analysis, Trilobatus sacculifer, Orbulina universa, Globigerinoides conglobatus, Globoconella inflata, Neogloboquadrina dutertrei, Globorotalia tumida, Menardella menardii and Truncorotalia truncatulinoides, span much of the morphological range of modern planktonic foraminifera and include forms with varying test-wall thickness (Fig. 1). Relative crushing resistance amongst

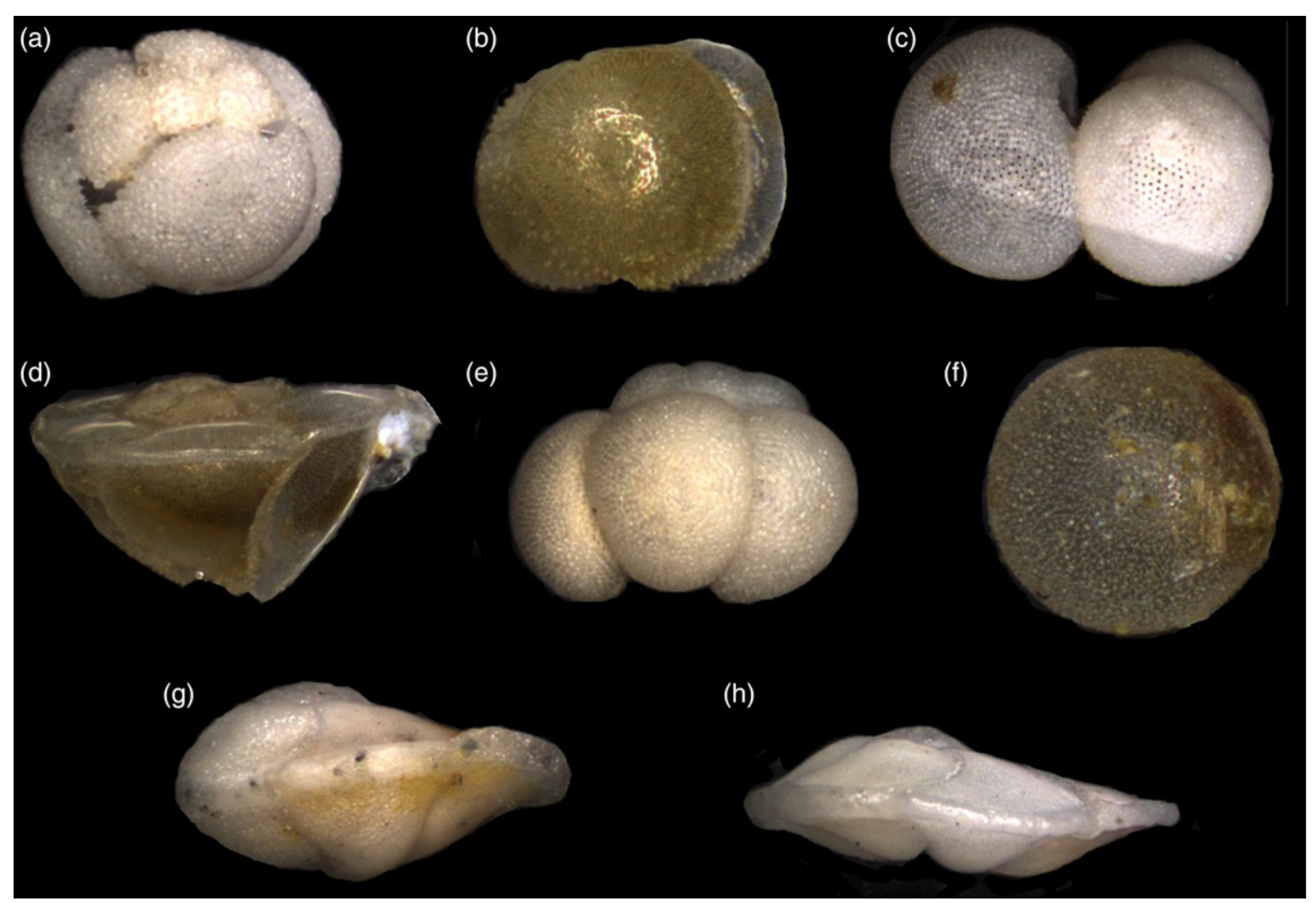

Fig. 1. Edge views of the eight species used in this study: (a) Globigerinoides conglobatus, (b) Globoconella inflate, (c) Trilobatus sacculifer, (d) Truncorotalia truncatulinoides, (e) Neogloboquadrina dutertrei, (f) Orbulina universa, (g) Globorotalia tumida and (h) Menardella menardii. 
taxa is then considered with regards to predation on planktonic foraminifera and preservation potential in the fossil record.

\section{Materials and methods}

Three samples (two core top and one tow) were picked for approximately 15 individual empty foraminiferal tests per target species for crushing experiments. A different subset of the eight target species was obtained from each sample locality, given the availability of species within that locality. The eight species targeted were chosen based on abundance, morphology and wall thickness, and included the globigerinoid foraminifer Trilobatus sacculifer (formerly Globigerinoides sacculifer, see Spezzaferri et al. (2015)); the spherical Orbulina universa; the calcite-encrusted globigerinoid Globigerinoides conglobatus; the rounded, cuboidal Neogloboquadrina dutertrei; the inflated, semi-conical chambered turborotalid Globoconella inflata; the keeled, biconvex globorotalid Globorotalia tumida; the keeled, compressed, thin-walled globorotalid Menardella menardii; and the conical globorotalid Truncorotalia truncatulinoides (Fig. 1). Species were identified based on the species concepts of Kennet \& Srinivasan (1983), with naming after Aze et al. (2011) (with the exception of T. sacculifer; Spezzaferri et al. (2015)).

Two types of samples were used: core-top samples and net-tow samples. The first was used to sample a range of abundant taxa and the second to test how gametogenic-calcite (added immediately prior to death) might influence our inferences. In the KC78 core-top sample, T. sacculifer, O. universa, G. tumida, N. dutertrei, $M$. menardii and $G$. conglobatus specimens were picked from the
$425-600$ and $600-710 \mu \mathrm{m}$ sieve size fractions. The KC78 coretop was sampled at $5.267^{\circ} \mathrm{N}$ by $44.133^{\circ} \mathrm{W}$ in the South Atlantic Ocean at a water depth of $3273 \mathrm{~m}$ by Woods Hole Oceanographic Institution (Sun et al. 2006), and provided by Bruce Corliss (University of Rhode Island, Graduate School of Oceanography). $\mathrm{KC} 78$ is a diverse assemblage dominated by the mixed-layer dwelling species $T$. sacculifer, with abundant $O$. universa, $M$. menardii and $G$. tumida in the size fractions picked. Two other species, $N$. dutertrei and G. conglobatus, although relatively rare, were also included in the study because of their distinct morphologies. The AII60-10 core top sample was provided by Richard Norris (Scripps Institution of Oceanography) and obtained from $29.660^{\circ} \mathrm{S}$ and $34.667^{\circ} \mathrm{W}$ at $1840 \mathrm{~m}$ water depth by the Woods Hole Oceanographic Institution's Atlantis II research vessel. Specimens of $O$. universa, T. truncatulinoides and G. tumida were picked from AII60-10. Three species, G. inflata, O. universa and $T$. truncatulinoides, were picked from two net tows and combined for this study: TAN1106/40 and TAN1106/50. The TAN1106/40 and TAN1106/50 localities were sampled at $48.796^{\circ} \mathrm{S}$ by $165.497^{\circ} \mathrm{W}$ from $<150 \mathrm{~m}$ water depth in 2011 by the National Institute of Water and Atmospheric Research's Solander Trough Cruise with a Multiple Opening/Closing Net and Environmental Sensing System (MOCNESS, Wiebe et al. 1976). Globoconella inflata, O. universa and T. truncatulinoides were very abundant in the $300-600 \mu \mathrm{m}$ size fraction and provide a 'living assemblage' test of our inferences otherwise made from postgametogenic core-top individuals. Yale Peabody Museum catalogue numbers (YPM\#) for all samples are listed in Table 1. All specimens from AII60-10 and TAN1106, and a number of

Table 1. Yale Peabody Museum accession number, species name, sample locality, size range, type and size, mean force at failure, coefficients of variation for failure force and wall thickness, mean wall thickness and relative crushing resistance for each sample based on force at failure

\begin{tabular}{|c|c|c|c|c|c|c|c|c|c|}
\hline YPM\# & Species & $\begin{array}{l}\text { Sample locality } \\
\text { (size range) }\end{array}$ & $\begin{array}{l}\text { Sample } \\
\text { type }\end{array}$ & $\begin{array}{c}\text { Number of } \\
\text { individuals }(n)\end{array}$ & $\begin{array}{c}\text { Force at } \\
\text { failure }(\mathrm{N})\end{array}$ & $\begin{array}{l}\text { Coeff. of } \\
\text { variation }\end{array}$ & $\begin{array}{c}\text { Mean wall } \\
\text { thickness }(\mu \mathrm{m})\end{array}$ & $\begin{array}{l}\text { Coeff. of } \\
\text { variation }\end{array}$ & $\begin{array}{l}\text { Relative } \\
\text { crushing } \\
\text { resistance }\end{array}$ \\
\hline IP.307890 & Globorotalia tumida & $\begin{array}{c}\text { AII60-10 } \\
(425-710 \mu \mathrm{m})\end{array}$ & Core top & 12 & 1.053 & 0.304 & 24.87 & 0.20 & Higher \\
\hline IP.307891 & Orbulina universa & $\begin{array}{c}\text { AII60-10 } \\
(425-710 \mu \mathrm{m})\end{array}$ & Core top & 12 & 0.419 & 0.419 & 29.43 & 0.44 & Normal \\
\hline IP.307892 & $\begin{array}{l}\text { Truncorotalia } \\
\text { truncatulinoides }\end{array}$ & $\begin{array}{c}\text { AII60-10 } \\
(425-710 \mu \mathrm{m})\end{array}$ & Core top & 12 & 1.26 & 0.284 & 18.82 & 0.18 & Higher \\
\hline IP.307893 & $\begin{array}{c}\text { Globigerinoides } \\
\text { conglobatus }\end{array}$ & $\begin{array}{c}\mathrm{KC} 78(425- \\
600 \mu \mathrm{m})\end{array}$ & Core top & 16 & 0.585 & 0.249 & 52.80 & 0.13 & Normal \\
\hline IP.307894 & Globorotalia tumida & $\begin{array}{c}\mathrm{KC} 78(425- \\
600 \mu \mathrm{m})\end{array}$ & Core top & 15 & 1.32 & 0.24 & 34.22 & 0.13 & Higher \\
\hline IP.307895 & Menardella menardii & $\begin{array}{c}\mathrm{KC} 78(425- \\
600 \mu \mathrm{m})\end{array}$ & Core top & 15 & 0.944 & 0.357 & 27.02 & 0.21 & Higher \\
\hline IP.307896 & $\begin{array}{c}\text { Neogloboquadrina } \\
\text { dutertrei }\end{array}$ & $\begin{array}{c}\mathrm{KC} 78(425- \\
600 \mu \mathrm{m})\end{array}$ & Core top & 17 & 0.618 & 0.182 & 39.18 & 0.31 & Normal \\
\hline IP.307897 & Orbulina universa & $\begin{array}{c}\mathrm{KC} 78(425- \\
600 \mu \mathrm{m})\end{array}$ & Core top & 16 & 0.499 & 0.374 & 20.17 & 0.32 & Normal \\
\hline IP.307898 & Trilobatus sacculifer & $\begin{array}{c}\mathrm{KC} 78(425- \\
600 \mu \mathrm{m})\end{array}$ & Core top & 16 & 0.475 & 0.29 & 29.97 & 0.20 & Normal \\
\hline IP.307899 & Menardella menardii & $\begin{array}{c}\text { KC78 }(600- \\
710 \mu \mathrm{m})\end{array}$ & Core top & 15 & 0.783 & 0.293 & 24.38 & 0.27 & Higher \\
\hline IP.307900 & Orbulina universa & $\begin{array}{c}\text { KC78 }(600- \\
710 \mu \mathrm{m})\end{array}$ & Core top & 14 & 0.575 & 0.317 & 38.70 & 0.36 & Normal \\
\hline IP.307901 & Trilobatus sacculifer & $\begin{array}{c}\mathrm{KC} 78(600- \\
710 \mu \mathrm{m})\end{array}$ & Core top & 12 & 0.463 & 0.256 & 33.31 & 0.22 & Normal \\
\hline IP.307902 & Globoconella inflata & $\begin{array}{c}\text { TAN1106 } \\
(300-600 \mu \mathrm{m})\end{array}$ & Tow & 15 & 0.421 & 0.277 & 11.64 & 0.29 & Normal \\
\hline IP.307903 & Orbulina universa & $\begin{array}{c}\text { TAN1106 } \\
(300-600 \mu \mathrm{m})\end{array}$ & Tow & 14 & 0.379 & 0.491 & 26.30 & 0.51 & Lower \\
\hline IP.307904 & $\begin{array}{l}\text { Truncorotalia } \\
\text { truncatulinoides }\end{array}$ & $\begin{array}{c}\text { TAN1106 } \\
(300-600 \mu \mathrm{m})\end{array}$ & Tow & 15 & 0.639 & 0.256 & 11.95 & 0.20 & Higher \\
\hline
\end{tabular}


individuals of $G$. tumida and M. menardii from $\mathrm{KC} 78$, were photographed from the umbilical view and measured along their major and minor axes prior to crushing using a stage micrometer and ImageJ software (Abramoff et al. 2004). The area of individually measured foraminifera was estimated by multiplying the major and minor axes. Wall thickness was measured by breaking off the final chamber (excluding kummerform chambers) of individual foraminifers from each species, imaging them so that a cross-section of the chamber wall was visible, and measuring the wall thickness using ImageJ.

To precisely measure crushing resistance of fossil foraminifera under compression, Pearson et al. (2015) used a Losenhausen servohydraulic testing machine with a $5 \mathrm{~N}$ Interface S-Beam load cell. For our study, we designed a relatively simple crushing rig to mount and crush foraminifera via incremental weight addition. Specimens were mounted on either their umbilical or spiral side, depending on which one provided the most stable (i.e. flat) surface. The mass needed to crush a test was determined by subsequent weighing of the weights after test failure, and the compressional force was calculated in Newtons as mass $\times$ acceleration (i.e. $9.807 \mathrm{~m} \mathrm{~s}^{-2}$ ). Many design iterations were explored, but the most effective apparatus was a tube constructed from $20 \mathrm{ml}$ plastic syringes (Fig. 2). The plunger of one syringe acts as a stage (Fig. 2f), to which a foraminifer is fixed, orientated dorso-ventrally, as pictured in Figure 1, with double-sided tape. Over this stage, a sleeve made from two syringes (Fig. 2d), guides a second plunger fitted with a metal peg (Fig. $2 b$ and c). The metal peg rests directly on the target foraminifer and applies the overlying weight to the

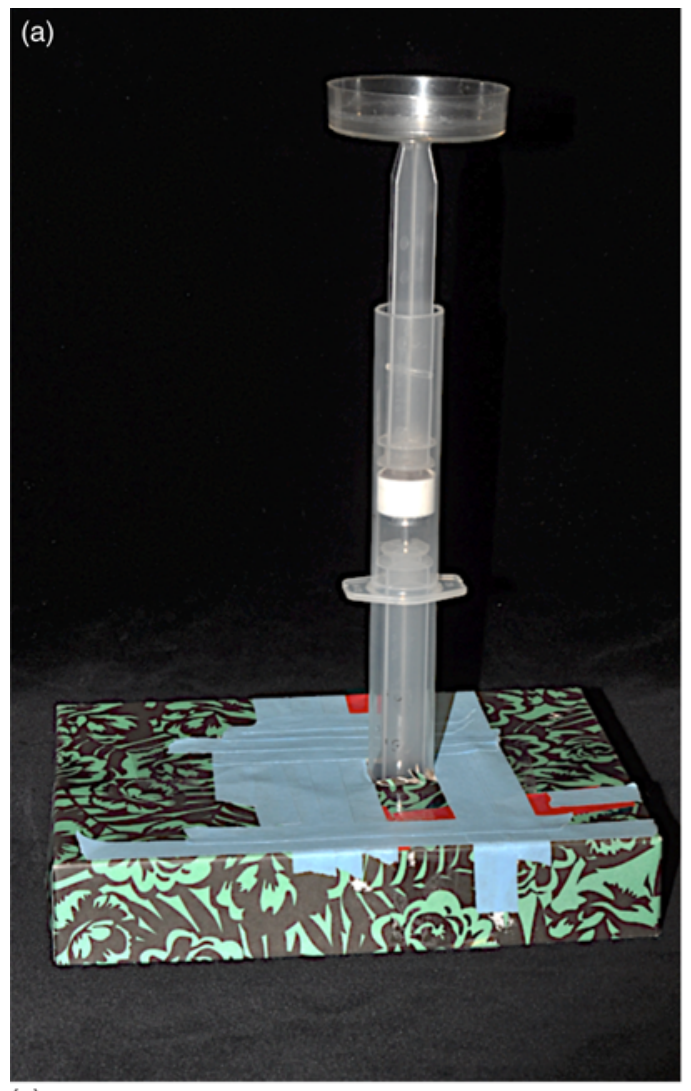

(b)

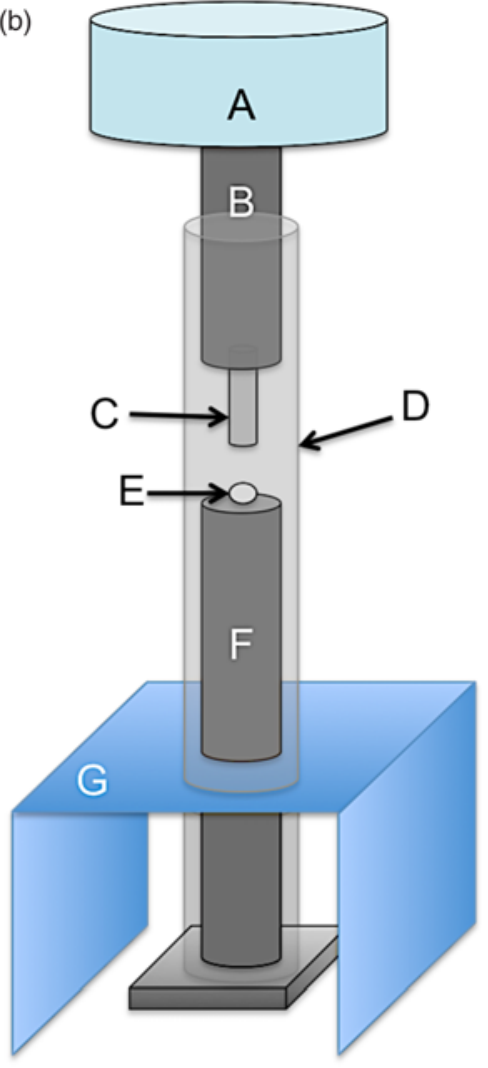

(c)

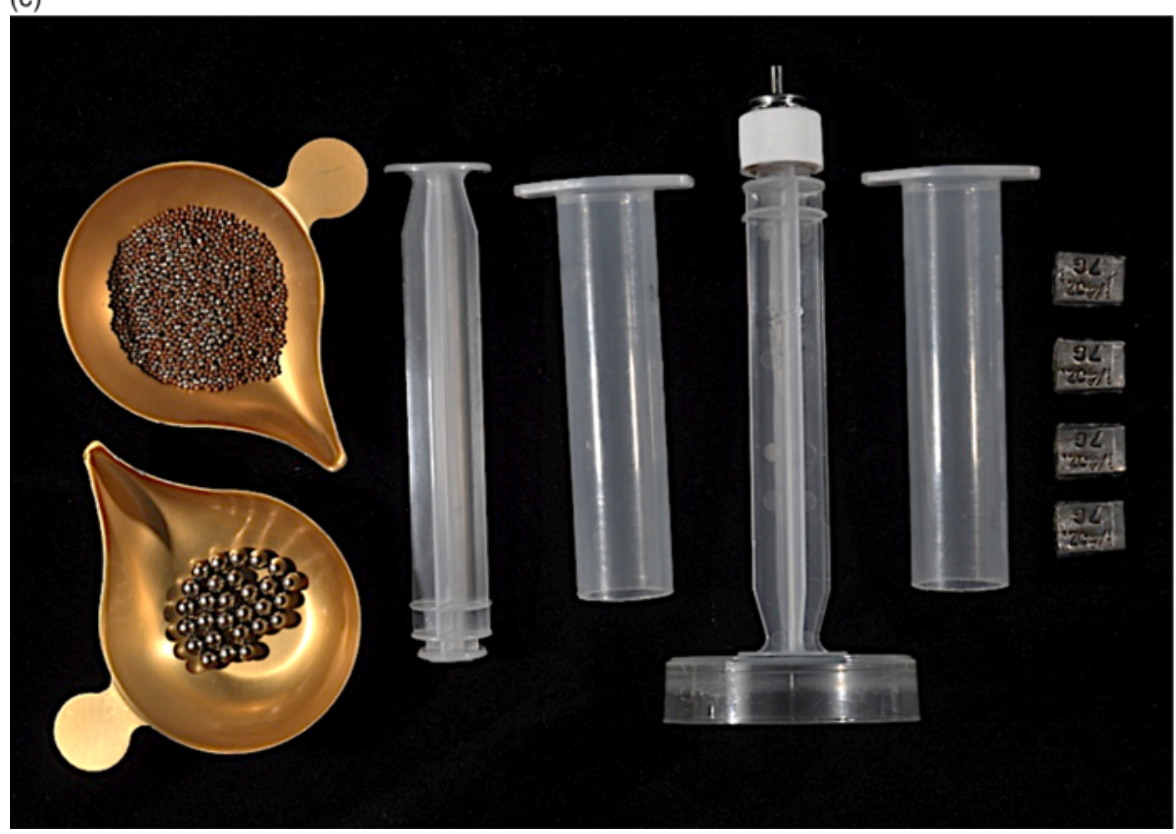

Fig. 2. Crushing rig: (a) photo and (b) sketch (not to scale). Crushing rig components in (b) labelled as follows: (A) weight collection dish, (B) upper plunger, (C) metal peg, (D) syringe sleeve, (E) specimen, (F) lower plunger/stage and (G) cardboard base (for stability). (c)

Additional and disassembled crushing rig components from left to right: brass scoops with 1 and $4 \mathrm{~mm}$ beads, syringe plunger (used as a stage, $F$ in $b$ ), cropped syringe sheath (D in b), syringe plunger with metal peg attached to one end and plastic dish attached to the other $(\mathrm{A}-\mathrm{C}$ in b), second cropped syringe sheath, $7 \mathrm{~g}$ lead weights. Photographs courtesy of the Yale Peabody Museum division of Invertebrate Zoology. 
specimen (Fig. 2). A small receptacle for weights rests on top of the second plunger (Fig. 2a). In each crushing experiment, small metal weights were carefully added to the dish until the specimen broke, causing the upper part of the rig to visibly drop. The combined mass of the weights at breakage and mass of the peg/plunger/dish apparatus were measured and converted to Newtons.

All statistical analyses were performed using built-in functions in RStudio version 0.97.55. To determine whether parametric or nonparametric statistics were appropriate, we tested the distribution of compressional forces for each species (by sample) for normality using the Shapiro-Wilk test. The data from two sample sets failed the tests of normality (see below for details), leading us to use nonparametric statistics. After deciding to use non-parametric statistics, we tested for significant differences among species and samples using a one-way Kruskal-Wallis ANOVA. Kolmogorov-Smirnov tests were then used to identify those pairs of taxa with significantly different compressional force distributions.

\section{Results}

Compressional force at crushing was measured for each species and case (core top or tow and size class) in $12-17$ individuals. All species showed variability in the distribution of crushing resistance values (Fig. 3; Table 1). For instance, the compression force at crushing for Trilobatus sacculifer individuals ranged from 0.249 to $0.726 \mathrm{~N}$. In most cases, the force needed to crush individuals of a given species were normally distributed (i.e. they failed to be rejected by a Shapiro-Wilk test for normality). The two exceptions were the towed Orbulina universa from TAN1106 and the core-top Trilobatus sacculifer from the $600-710 \mu \mathrm{m}$ sieve size fraction of KC78. Because these two cases failed the Shapiro-Wilk test for normality, non-parametric statistics were used.

Within species groups and localities, the relationship between test area and compressional force at failure was weak or non-existent. Across all individuals, compressional force at failure was significantly correlated with test area $(P$-value $=0.0001)$, but the variance explained was low $\left(r^{2}=0.121\right)$. When analysed by species and locality, no locality or species had a significant relationship between test area and failure force.

Similarly, a linear regression detected no significant relationship between mean test thickness and the mean force at failure for each species from each locality $\left(r^{2}=0.003, P=0.852\right.$, Fig. 4). Within samples, $O$. universa typically had among the highest test wall-thicknesses measured (Table 1, Supplementary Table 3). Orbulina universa and G. tumida were significantly thicker that T. truncatulinoides in the AII60-10 core top sample. Orbulina

Core Top (KC78)
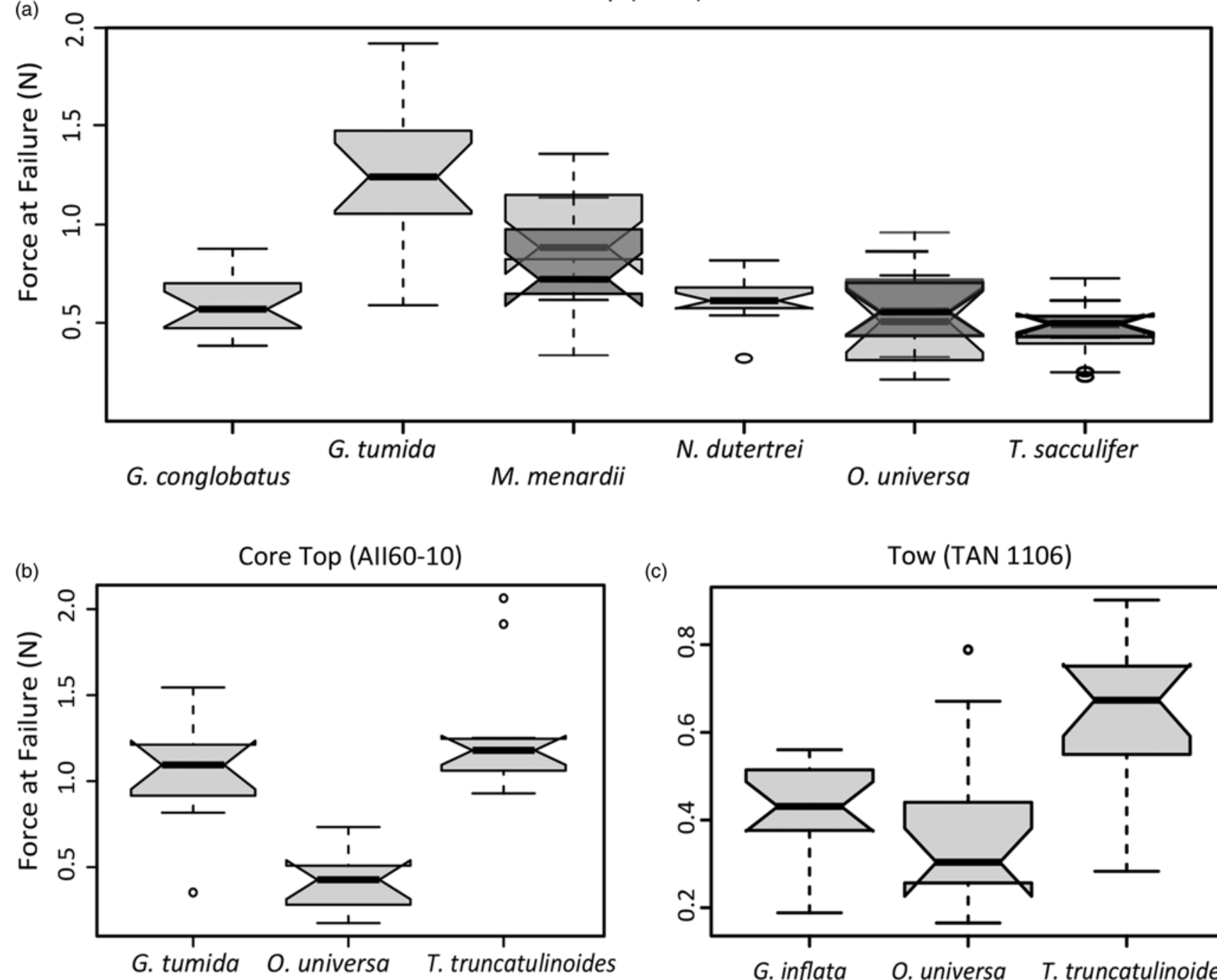

(c)

Tow (TAN 1106)

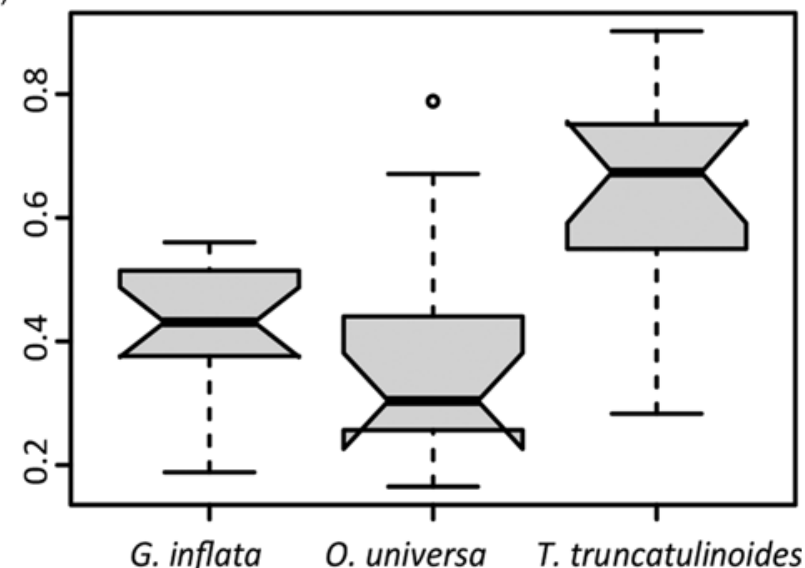

Fig. 3. Boxplots of failure weight distributions for all species groups by sample group. Boxplot notches indicate a $95 \%$ confidence interval on the median. (a) Core-top sample KC78, (b) core-top sample AII 60-10 and (c) MOCNESS tow sample TAN1106. In (a) the two size fractions of KC78 are overlain, with the smaller size fraction $(425-600 \mu \mathrm{m})$ in light grey and the larger size fraction $(600-710 \mu \mathrm{m})$ in dark grey. 


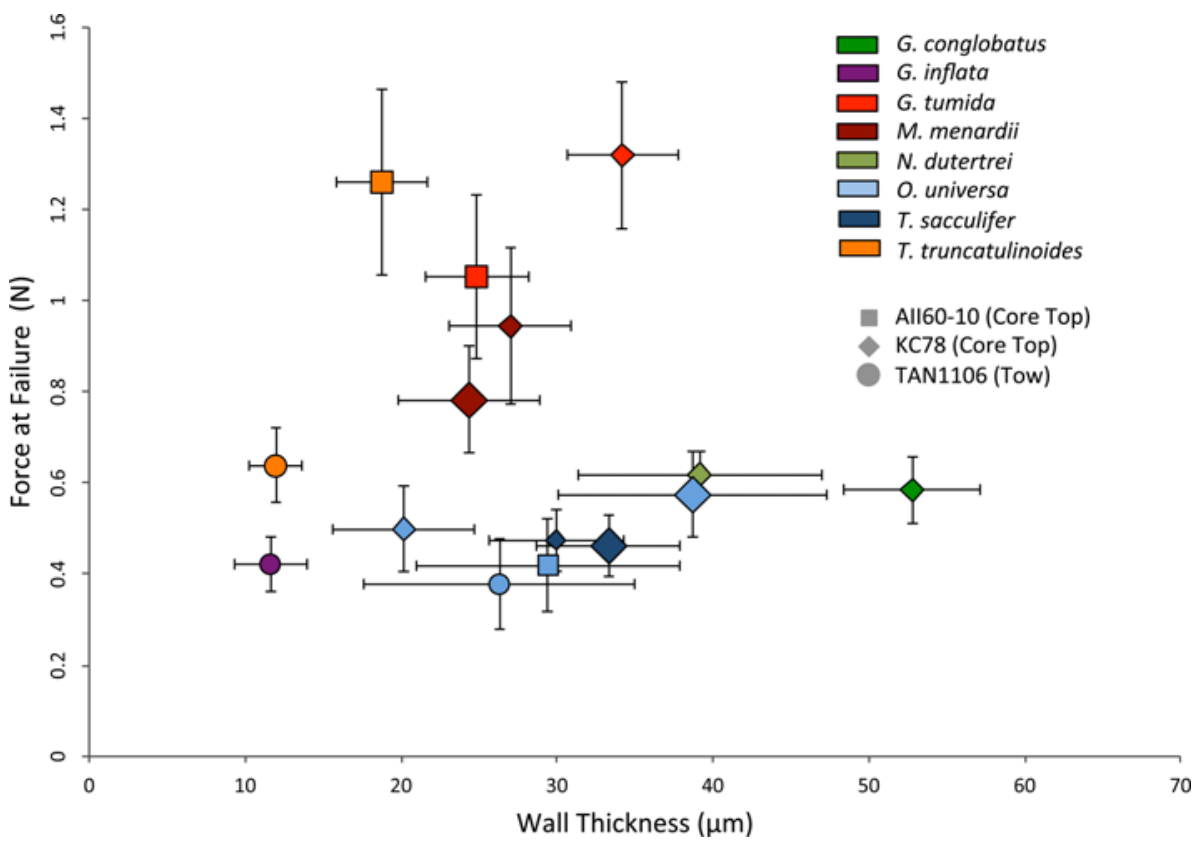

Fig. 4. Average values for wall thickness and force at failure for each species group from each locality, with $95 \%$ confidence intervals denoted by error bars. There is no significant relationship between the thickness of the final chamber and resistance to compressive force. For $\mathrm{KC} 78$, the larger diamond icons indicate averages from the $600-710 \mu \mathrm{m}$ size fraction and the smaller diamond icons indicate averages from the $425-600 \mu \mathrm{m}$ size fraction. universa was also significantly thicker than the other species in the towed sample, TAN1106. In the larger size fraction of KC78, $O$. universa was thicker on average than the other species in the larger size fraction of KC78, but not significantly so. Finally, G. conglobatus was significantly thicker than all other species in the smaller size fraction of KC78. Variation in wall thickness was high, with coefficients of variation as high as 0.51 for the towed specimens of $O$. universa from TAN1106. Globigerinoides conglobatus and $G$. tumida from KC78 (425-600 $\mu \mathrm{m}$ size fraction) had the lowest coefficients of variability $(0.13)$.

Significant differences in the distribution of the crushing resistance of species were tested with a one-way Kruskal-Wallis ANOVA for each case ( $P$-values in Table 2$)$. Kolmogorov-Smirnov tests (Supplementary Table 2) were then used to determine which pairwise comparisons were statistically different. The conical and biconvex species were significantly more resistant to crushing under compression as compared to the other species in all samples tested. In the core-top KC78, G. tumida $(\mu=1.32 \mathrm{~N})$ and M. menardii $(\mu=$ $0.944 \mathrm{~N}$ ) were significantly more resistant to compressional force than all other species $(P$-value $<0.001)$ by $48 \%$ on average, but did not differ significantly from one another $(P$-value $=0.076)$. A separate Kruskal-Wallis test of the four relatively weak species from KC78, O. universa $(\mu=0.499 \mathrm{~N}), G$. conglobatus $(\mu=0.585 \mathrm{~N})$, $N$. dutertrei $(\mu=0.618 \mathrm{~N})$ and $T$. sacculifer $(\mu=0.475 \mathrm{~N})$, also found significant differences amongst species $(P$-value $=0.017$; see Supplementary Table 2 for pairwise ). In the core top AII60-10, $G$. tumida and $T$. truncatulinoides were significantly more resistant (36\% on average) to crushing force than $O$. universa ( $P$-value $<0.001)$, with mean crushing forces of 1.053, 1.26, and $0.419 \mathrm{~N}$, respectively. Similarly, in the TAN1106 towed sample, T. truncatulinoides was significantly more resistant $(63 \%$ on average) to crushing force than the $O$. universa and $G$. inflata

Table 2. Results of Kruskal-Wallis analysis of variance for each sample group

\begin{tabular}{lcccc}
\hline Sample locality & Size range $(\mu \mathrm{m})$ & Sample type & Chi squared & $P$ value \\
\hline AII 60-10 & $425-710$ & Core top & 19.320 & $<0.001$ \\
KC78 425-600 & $425-600$ & Core top & 56.380 & $<0.001$ \\
KC78 600-710 & $600-710$ & Core top & 24.618 & $<0.001$ \\
TAN1106 & $300-600$ & Tow & 15.357 & $<0.001$ \\
\hline
\end{tabular}

( $P$-value $<0.001$ ), with mean crushing forces of $0.639,0.421$, and $0.379 \mathrm{~N}$ respectively. In the same sample, $O$. universa crushed under significantly less force than $G$. inflata. Across samples, G. tumida, M. menardii and T. truncatulinoides were significantly more resistant to crushing force than the other species tested (Supplementary Table 2).

Orbulina universa was present in all four cases examined (coretop KC78 425-600 $\mu \mathrm{m}$, core-top KC78 $600-710 \mu \mathrm{m}$, core-top AII60-10 and tow TAN1106) and consistently showed the greatest variability in compressional force, as indicated by the coefficient of variation $(0.374$ v. $0.182-0.357$ for core-top KC78 $425-600 \mu \mathrm{m}$; 0.317 v. $0.256-0.293$ for core-top KC78 $600-710 \mu \mathrm{m}$; 0.419 v. $0.284-0.304$ for core-top AII60-10; and 0.491 v. $0.256-0.277$ for tow TAN1106). There was no significant difference in the force needed to crush $O$. universa in the three core-top samples (Fig. 5). Average crushing force for $O$. univers $a$ was $0.379 \mathrm{~N}$ (median= $0.304 \mathrm{~N})$ in the tow sample TAN1106, $0.499 \mathrm{~N}($ median $=0.506 \mathrm{~N})$ in the $425-600 \mu \mathrm{m}$ size fraction of core-top KC78, and $0.419 \mathrm{~N}$ (median $=0.427 \mathrm{~N}$ ) in core-top AII60-10. The towed O. universa from TAN1 106 were significantly weaker $(\mu=0.575 \mathrm{~N}$, median $=$ $0.561 \mathrm{~N})$ than the $O$. universa individuals in the largest size fraction of $\mathrm{KC} 78(P$-value $=0.037)$.

\section{Discussion}

Modern planktonic foraminifera differ in their resistance to crushing, as measured by mean compressional force at test failure. Of the eight species tested, the most resistant species were Menardella menardii, Globorotalia tumida and Truncorotalia truncatulinoides, which have biconvex keeled (M. menardii and G. tumida) and conical keeled (T. truncatulinoides) morphologies. For instance, in the core-top sample $\mathrm{KC} 78, M$. mendardii and $G$. tumida were on average 1.5 and 2 times more resistant to crushing than the next most resistant species, Neogloboquadrina dutertrei, in the $425-600 \mu \mathrm{m}$ size fraction. More generally, biconvex and conical species had between 1.4 and 3 times the compressional strength of the more globular species (Tables 1,2 and Results) and this compressional strength was unrelated to variation in wall thickness across species (Table 1; Fig. 4).

The aim of this study was to understand how mean compressional force at test failure varies amongst species and how this might affect (and reflect) their ecology. For this, the comparison between core- 
(a)

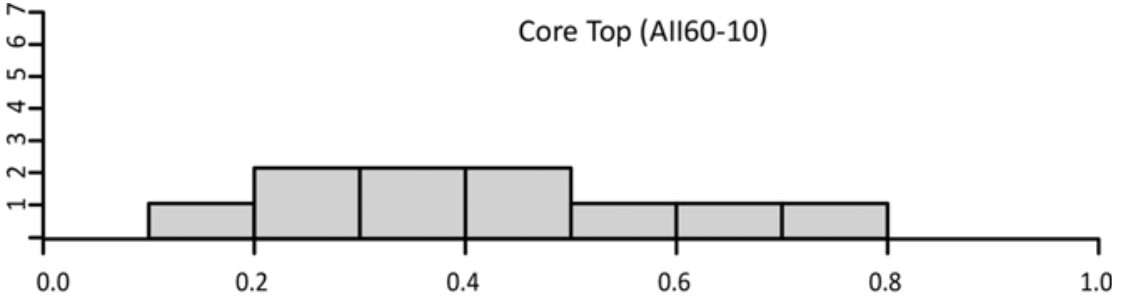

(b)

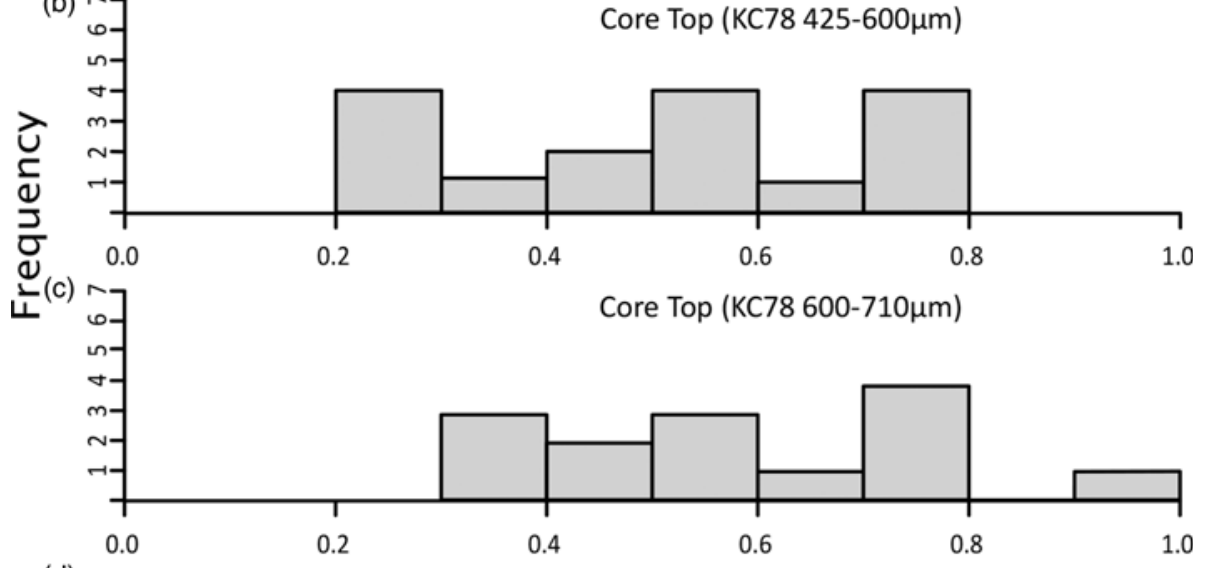

(d) $r$

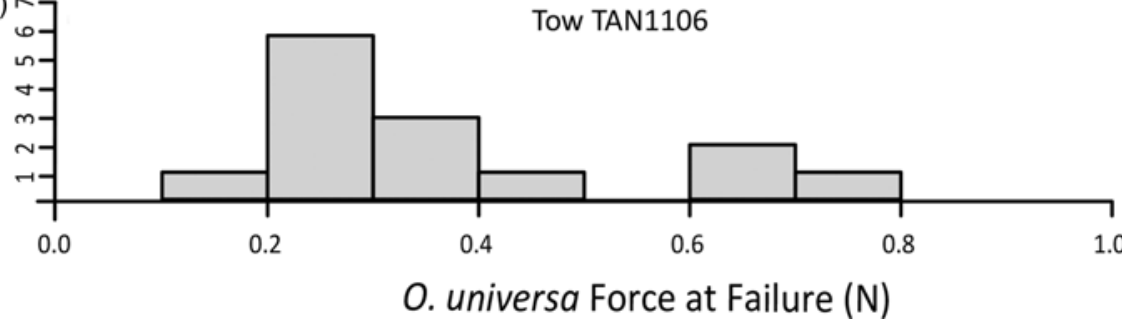

Fig. 5. Distribution of compressional force at failure for Orbulina universa in all four sample groups: (a) core-top AII 60-10; (b) core-top KC78 425-600 $\mu$; (c) core-top KC78 $600-710 \mu \mathrm{m}$; (d) MOCNESS tow TAN1106. Failure force distributions of $O$. universa samples are not significantly different from one another. top and tow samples is important. Individuals from tow samples were pre-gametogenic. That is, they had yet to reproduce and add the extra layer of calcite that thickens planktonic foraminiferal tests immediately prior to death. We expected that the effect of gametogenesis would be to generally strengthen the foraminiferal test. Following on these expectations, T. truncatulinoides from the tow sample were significantly less resistant to crushing than those from the AII60-10 core top ( $P$-value $<0.001$; Fig. 3$)$. In addition, failure weights for the towed, pre-gametogenic individuals of $O$. universa were noticeably skewed toward lower compressional forces (Fig. 5), although pairwise Kolmogorov-Smirnov tests failed to distinguish amongst core-top and towed samples of $O$. universa. Counter to our expectation regarding gametogenic calcification, compressional forces were relatively low in the second core-top sample for all species (AII60-10) and comparable to that of the tow sample (see Figs 3b, c and 5). This pattern remains unexplained and could indicate a number of things, including a relatively minor role of post-gametogenic wall thickening in the species tested at AII6010 , a relatively greater importance of intraspecific variation in crushing resistance, or relatively poor preservation at AII60-10 as compared to KC78 (note: visual inspection suggested excellent 'glassy' preservation at both core-top sites).

Importantly, we found significant differences in crushing resistance among pre-gametogenic species in the tow sample. Specifically, T. truncatulinoides was significantly more resistant, at least 1.5-fold stronger, than $O$. universa and $G$. inflata. As with the core-top sample, this significant difference in the mechanical strength existed between the conical $T$. truncatulinoides and globular/spherical morphologies of $O$. universa and $G$. inflata. Although the rest of our comparisons were in core-top individuals, and likely on post-gametogenic individuals, the tow data suggest that the relative relationship amongst species is maintained. In other words, relatively resistant core-top morphologies were also likely relatively hard to crush when living.

In all species measured, we observed a wide variation in the crushing resistance of individuals. Pearson et al. (2015) also observed wide variation in the force at first cracking of tests (forces ranged from 0.2 to $1.7 \mathrm{~N}$ ) and they hypothesized that this may have been due to undetected wall-defects (cracks) in some individuals. A second possible source of variation is measurement error introduced by the relatively simple crushing rig used here. Weights were added sequentially, with the heaviest weights ( $7 \mathrm{~g}$ lead tabs) being utilized only on the must rugged specimens of G. tumida, M. menardii and post-gametogenic T. truncatulinoides. At times, additional weight of up to $7 \mathrm{~g}$ may have been added after test failure. This source of error is relatively small as compared to the standard deviation of failure weights (standard deviations ranged from 11 to $48 \mathrm{~g}$ ). Additionally, mounting position is critical, but the most difficult to mount specimens (biconvex taxa G. tumida and M. menardii) do not have the highest coefficients of variation, suggesting that this is not a large source of variation.

We suspect that intraspecific variation in test construction and wall thickness may account for some of the within-species variation in crushing resistance observed. For instance, $O$. universa had the greatest variation in mean weight at failure of all species tested (Table 1; Figs $3-5$ ). This broad variation may relate to the known occurrence of 'thin-' and 'thick-'walled morphotypes of $O$. universa, perhaps coinciding with cryptic species (Hamilton et al. 2008; Morard et al. 2009; Marshall et al. 2015). In our four samples, we found wall thicknesses of $O$. universa to range from 14.4 to $49.3 \mu \mathrm{m}$ (Fig. 4; Table 1, Supplementary Table 3). However, even though high variability of resistance to crushing and high variability in wall thickness were associated in $O$. universa, wall thickness overall was a poor predictor of crush resistance across species 


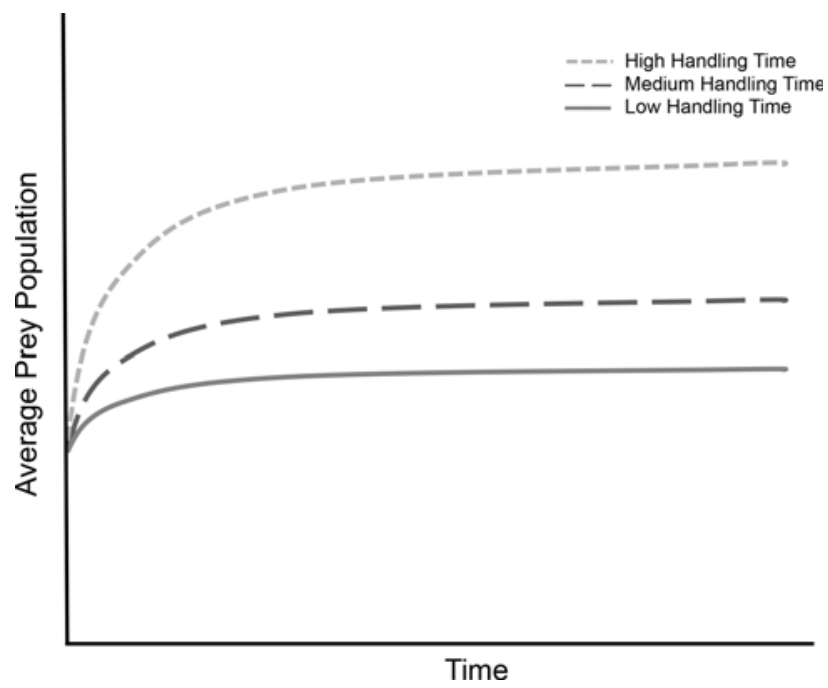

Fig. 6. A theoretical sketch of the effect of crushing resistance on average prey population size. Predation pressure is illustrated for three populations with different predator handling times based on Lotka-Volterra models described in Stevens (2009) and handling time disparities after the range observed in Chang \& Hanazato (2005) for water fleas and copepods.

(Fig. 4). In many cases, the most crush-resistant species in a sample was, in fact, one of the thinnest walled. For example in the AII60-10 core-top sample, T. truncatulinoides has the thinnest walls and the highest compressional force at failure. Similarly, in the towed TAN1106 sample, T. truncatulinoides requires the highest compressional force to crush and has among the thinnest average testwalls. This suggests that gross morphology, or the shape and the arrangement of the preceding chambers, is key to crush resistance, and not wall thickness.

If higher crushing resistance in planktonic foraminifera leads to higher handling time during attempted predation, and higher handling time results in reduced mortality as it does in other groups (Boulding 1984; Chang \& Hanazato 2005), then a fitness advantage may be conferred on relatively hard to crush species. In Figure 6, the potential of handling time to affect survivorship of different planktonic foraminiferal species is imagined in a sketch of idealized prey populations with differing crushing resistance under predation. This figure was constructed with Lotka-Voltera type coupled equations, as in Stevens (2009), which model the interdependent fluctuations of two populations linked by trophic interactions. In general, higher handling times should reduce prey consumption per unit time and lead to higher average population sizes and survivorship over time (Fig. 6). Populations of planktonic foraminifera might be expected to show this type of behaviour even if most of their mortality was due to non-selective predators. This is because predation by large filter feeders would exert a constant, non-selective pressure on all morphotypes, with just the selective feeding driving the difference in mortality between species. Future evaluation of this predation hypothesis is needed to directly parameterize the relationship between shape and handling time, feeding anatomy of potential predators and the relative importance of other traits, such as spines and palatability. Additionally, we measured compressional strength on the spiral-umbilical axis, but reinforced features such as the keel suggest that the greatest forces experienced in nature may occur in other orientations. Further crushing and feeding experiments could provide more specific insight into the repeated evolution of keels and other features.

Mean compression strength can also have taphonomic effects, influencing the porosity of sediments and the composition of fossil foraminiferal assemblages (i.e. Pearson et al. 2015). Berger \& Piper (1972) explored the differences in dissolution susceptibility as well as sinking and settling speed in relation to preservation potential. Here we can add crushing resistance to the taphonomic data of Berger \& Piper (Table 3, note: compressional strength is considered here independently of subsequent dissolution effects), highlighting the particularly low preservation potential of some taxa ( $T$. sacculifer and $O$. universa) as compared to others (i.e. G. tumida). Berger \& Piper noted that poorly preserved sediments had higher counts of G. tumida than unaltered sediments. Crushing resistance, in addition to solubility and sinking speed, might contribute to this trend, as many of the species that were identified by Berger \& Piper as having low preservation potential are also the species that displayed low crushing resistance in this study.

\section{Conclusion}

We have shown that modern planktonic foraminifera vary in their resistance to crushing, as measured by the mean compressional force at mechanical failure. Biconvex, keeled and conical forms, morphotypes that convergently evolved multiple times in the evolutionary history of planktonic foraminifera, are significantly more resistant to crushing than the other morphologies tested. Such resistance could increase the viability of living populations under selective predation, thereby providing a driving force behind the repeated evolution of certain morphologies.

\section{Acknowledgements and Funding}

We thank R. Norris (Scripps Institution of Oceanography), B. Corliss (University of Rhode Island), M. Henehan and H. Bostock (National Institute of Water and Atmospheric Research) for collecting and contributing the core-top and tow samples that made this study possible. We thank A. Hsiang, D. Penman, L. Elder and D. Evans of the Hull Lab at Yale University for valuable feedback on this manuscript. We also thank S. McMahon (Yale University) for advice on the construction of the crushing rig and E. Lazo-Wasem of the Yale Peabody Museum Division of Invertebrate Zoology for photographing the crushing rig. The basis for this study was initially conceived as a course project for Derek Brigg's (Yale University) 'Exceptional Glimpses of Past Life' class in the autumn

Table 3. Taphonomic potential

\begin{tabular}{|c|c|c|c|c|}
\hline & Sinking speed $(1=$ slowest $)$ & Solubility $(1=$ most soluble $)$ & Crushing resistance & Relative preservation potential \\
\hline Globigerinoides conglobatus & 5 & 2 & Medium & Medium \\
\hline Globoconella inflata & 7 & 5 & Medium & Medium \\
\hline Globorotalia tumida & 8 & 8 & High & High \\
\hline Menardella menardii & 5 & 6 & High & High \\
\hline Neogloboquadrina dutertrei & 6 & 7 & Medium & High \\
\hline Orbulina universa & 1 & 3 & Low & Low \\
\hline Trilobatus sacculifer & 2 & 1 & Low & Low \\
\hline Truncorotalia truncatulinoides & 3 & 4 & High & Medium \\
\hline
\end{tabular}

Sinking speed and solution rankings from Berger \& Piper (1972), crushing resistance from experimental results in Table 1 (least crushable $=$ high). Relative preservation potential was calculated by combining all three preceding factors into a single score and placing each species into one of three categories. 
of 2014. This material is based upon work supported by the National Science Foundation Graduate Research Fellowship under Grant No. DGE-1122492.

\section{Scientific editing by Sigal Abramovich}

\section{References}

Abramoff, M.D., Magalhaes, P.J. \& Ram, S.J. 2004. Image processing with ImageJ. Biophotonics International, 11, 36-42.

Aze, T., Ezard, T.H.G., Purvis, A., Coxall, H.K., Stewart, D.R.M., Wade, B.S. \& Pearson, P.N. 2011. A phylogeny of Cenozoic macroperforate planktonic foraminifera from fossil data. Biological Reviews, 86, 900-927.

Bé, A.W.H. \& Hutson, W. 1977. Ecology of planktonic foraminifera and biogeographic patterns of life and fossil assemblages in the Indian Ocean. Micropaleontology, 23, 369-414.

Berger, W. \& Piper, D. 1972. Planktonic foraminifera: differential settling, dissolution, and redeposition. Limnology and Oceanography, 17, 275-287.

Boulding, E.G. 1984. Crab-resistant features of shells of burrowing bivalves: Decreasing vulnerability by increasing handling time. Journal of Experimental Marine Biology and Ecology, 76, 201-223.

Caromel, A.G.M., Schmidt, D.N., Phillips, J.C. \& Rayfield, E.J. 2014. Hydrodynamic constraints on the evolution and ecology of planktic foraminifera. Marine Micropaleontology, 106, 69-78.

Chang, K.W. \& Hanazato, T. 2005. Prey handling time and ingestion probability for Mesocyclops sp. predation on small cladoceran species Bosmina longirostris, Bosminopsis deitersi, and Scapholeberis mucronata. Limnology, 6, 39-44.

Cifelli, R. 1969. Radiation of Cenozoic planktonic foraminifera. Systematic Zoology, 18, 154-168.

Coxall, H.K., Wilson, P.A., Pearson, P.N. \& Sexton, P.F. 2007. Iterative evolution of digitate planktonic foraminifera. Paleobiology, 33, 495-516.

Hamilton, C.P., Spero, H.J., Bijma, J. \& Lea, D.W. 2008. Geochemical investigation of gametogenic calcite addition in the planktonic foraminifera Orbulina universa. Marine Micropaleontology, 68, 256-267.

Hamm, C.E., Merkel, R., Springer, O., Jurkojc, P., Maier, C., Prechtel, K. \& Smatecek, V. 2003. Architecture and material properties of diatom shells provide effective mechanical protection. Nature, 421, 841-843.

Hemleben, C., Spindler, M. \& Anderson, O.R. 1989. Modern planktonic foraminifera. Springer, Berlin.

Holling, C.S. 1959. Some characteristics of simple types of predation and parasitism. Canadian Entomologist, 91, 385-398.

Jeschke, J.M., Kopp, M. \& Tollrian, R. 2002. Predator functional responses: Discriminating between handling and digesting prey. Ecological Monographs, 72, 95-112.

Katz, C.H. 1985. A nonequilibrium marine predator-prey interaction. Ecology, 66, $1426-1438$

Kennett, J.P. \& Srinivasan, M.S. 1983. Neogene Planktonic Foraminifera: a Phylogenetic Atlas. Hutchison Ross, Stroudsburg.
Lipps, J.H. 1979. Ecology and paleoecology of planktic foraminifera Foraminiferal Ecology and Paleoecology. The Society of Economic Paleontologists and Mineralogists: Short Course Notes, 6, 62-104.

Loeblich, A.R. \& Tappan, H. 1964. Treatise on Invertebrate Paleontology, Part C: Protista 2 - Sarcodina, Chiefly 'Thecamoebians' and Foraminiferida. Moores, R.C. (ed.) Geological Society of America and University of Kansas Press.

Marsalek, D.S., Wright, R.C. \& Hay, W.W. 1969. The function of the test in foraminifera. Transactions Gulf Coast Association of Geological Societies, 19, 342-352

Marshall, B.J., Thunnell, R.C., Spero, H.J., Henehan, M.J., Lorenzoni, L. \& Astor, Y. 2015. Morphometric and stable isotopic differentiation of Orbulina universa morphotypes from the Cariaco Basin, Venezuela. Marine Micropaleontology, 120, 46-64.

Morard, R., Quillevere, F., Escarguel, G., Ujiie, Y., de Garidel-Thoron, T., Norris, R.D. \& de Vargas, C. 2009. Morphological recognition of cryptic species in the planktonic foraminifer Orbulina universa. Marine Micropaleontology, $\mathbf{7 1}$ $148-165$.

Norris, R. 1991. Biased extinction and evolutionary trends. Paleobiology, 17, 388-399.

Pearson, P.N., Evans, S.L. \& Evans, J. 2015. Effect of diagenetic recrystallization on the strength of planktonic foraminifer tests under compression. Journal of Micropalaeontology, 34, 59-64, http://doi.org/10.1144/jmpaleo2013-032

Smetacek, V. 2001. A watery arms race. Nature, 411, 745.

Spezzaferri, S., Kucera, M. et al. 2015. Fossil and genetic evidence for the polyphyletic nature of the planktonic foraminifera 'Globigerinoides', and description of the new genus Trilobatus. PLoS One, 10, e 0128108.

Stevens, M.H.H. 2009. A Primer of Ecology with R. Springer, New York.

Sun, X., Corliss, B.H., Brown, C.W. \& Showers, W.J. 2006. The effect of primary productivity and seasonality on the distribution of deep-sea benthic foraminifera in the North Atlantic. Deep Sea Research I, 53, 28-47.

Thompson, D.W. 1961. On Growth and Form. Cambridge University Press, Cambridge.

Tyszka, J. 2006. Morphospace of foraminiferal shells: Results from the moving reference model. Lethaia, 39, 1-12.

Tyszka, J. \& Topa, P. 2005. A new approach to modeling foraminiferal shells Paleobiology, 31, 522-537.

Werner, E.E. \& Hall, D.J. 1979. Foraging efficiency and habitat switching in competing sunfishes. Ecology, 60, 256-264.

Whetmore, K.L. 1987. Correlations between test strength, morphology and habitat in some benthic foraminifera from the coast of Washington. Journal of Foraminiferal Research, 17, 1-13.

Whetmore, K.L. \& Plotnick, R.E. 1992. Correlations between test morphology, crushing strength, and habitat in Amphistegina gibbosa. Archaias angulatus, and Laevipeneroplis proteus from Bermuda. Journal of Foraminiferal Research, 22, 1-12.

Wiebe, P.H., Burt, K.H., Boyd, S.H. \& Morton, A.W. 1976. A multiple opening/ closing net and environmental sensing system for sampling zooplankton. Journal of Marine Research, 34, 313-326. 